\title{
Lung Cancer Treatment: Status 2015
}

\section{Kirill Neumann*}

Medical Doctor, The Intervention Centre, Norway

"Corresponding author: Kirill Neumann, Medical Doctor, The Intervention Centre, Norway, Tel: 46261495; E-mail: kirill.neumann@gmail.com

Received date: June 04, 2015; Accepted date: June 16, 2015; Published date: June 24, 2015

Copyright: () 2015 Kirill Neumann. This is an open-access article distributed under the terms of the Creative Commons Attribution License, which permits unrestricted use, distribution, and reproduction in any medium, provided the original author and source are credited.

\section{Introduction}

Lung cancer used to be extremely rare in the beginning of the 20th century. Nowadays it is one of the most frequent cancer types, and it is estimated that about 1.6 million people are diagnosed with lung cancer annually [1]. And definitely a killer number one among all cancer types, standing for as much as $30 \%$ of all cancer related deaths in the world. Up to $80 \%$ of lung cancer patients have an advanced disease at the time of diagnosis and overall survival of $10-15 \%$ was over a long time used as an example of meaningless and failure of our attempts in war against cancer [2].

The main treatment option in non-small cell lung cancer (NSCLC) is surgical resection whenever possible, sometimes combined with chemotherapy or radiation therapy, but these tumours are typically not very susceptible to that sort of treatment. It is the opposite for small cell lung cancer (SCLC) that is usually quite responsive to chemotherapy and radiation therapy, but is generally more aggressive and gives metastases earlier, so surgery is rarely an option. This is a combination treatment that we have had for decades until 1990's. We've got a third generation chemotherapy that improved median survival in these patients with a couple of months. In a paper from 2002 the authors stated that "we have reached the maximum potential with lung cancer treatment" [3].

Luckily, the last decade has shown us that it is not the case. It turned out that if we start to survey cancer related genes in adenocarcinoma, a subtype of NSCLC, we can discover that more than half part of these tumours possess some sort of mutations in these oncogenes [4]. Mutations in genes EGFR, EML4-ALK and KRAS are the most frequent and have to the date most importance when it comes to treatment.

The prior one is most interesting when it comes to treatment possibilities available to the date.

EGFR stands for epidermal growth factor receptor. It is a type of protein that uses a signalling cascade of tyrosine kinase to control cell division. When it becomes mutant, it serves as an oncogene, making the receptor overactive and therefore making the cell to divide uncontrolled. The reason we are introducing the new term - Tyrosine Kinase - is because if we block its activity, we turn off this cascade.
And the novel treatment possibility is a group of drugs named Tyrosine Kinase Inhibitors [5].

The drugs were first tested on the NSCLC population in 2004, and it turned out that patients with mutant EGFR gene can have response rate as high as $80 \%$. This mutation is most often observed in females, non-smokers and East Asians. There is consistent evidence on the tyrosine kinase inhibitor treatment from several trials that have shown better efficiency, less toxicity and better tolerance in the selected group of patients that have a mutant EGFR. Because of their efficiency, the tyrosine kinase inhibitors are now introduced as the first line therapy in patients with known EGFR mutant adenocarcinoma. There are three drugs registered in Europe, called Gefitinib, Erlotinib and Afatinib. The latter was synthesized several years later than the prior two, and the main difference is that Afatinib is an irreversible inhibitor that binds to the EGFR receptor permanently. It has shown effect even in patients with acquired resistance to Gefitinib and Erlotininb [6,7].

There is another target oncogene that is already actively used in personalised treatment. It is called EML4-ALK - a fusion gene present in some 5 to $7 \%$ of adenocarcinomas. It too can mutate into an oncogene. Interestingly, in a paper from 2009 the researches stated that "the role of this oncogene is yet unknown and practical use is unclear". Only 2 years later we got a new tyrosine kinase inhibitor that targets this ALK translocate oncogene. The drug is named Crizotinib and it has shown a survival benefit in these patients. And another one, Ceritinib came in 2014 and there are few more under development [8].

The biggest group of known mutant oncogenes is a gene called KRAS. It is quite frequent and can be seem in about one quarter of all adenocarcinomas. However, the presence of this oncogene has been related to primary resistance to tyrosine kinase inhibitor treatment. The most recent news however is that there is a study from 2014, where the scientists found out that if one can address some related pathways instead of targeting the KRAS directly that can have certain positive effect in a small subset of patients. No agents are approved for this cohort to the date, there is a phase II trial on Selumetinib that has shown some benefit, and phase 3 is on the way. And there are some less frequent mutations, and their practical use in treatment of lung cancer is to the date not clear [9] (Figure 1). 


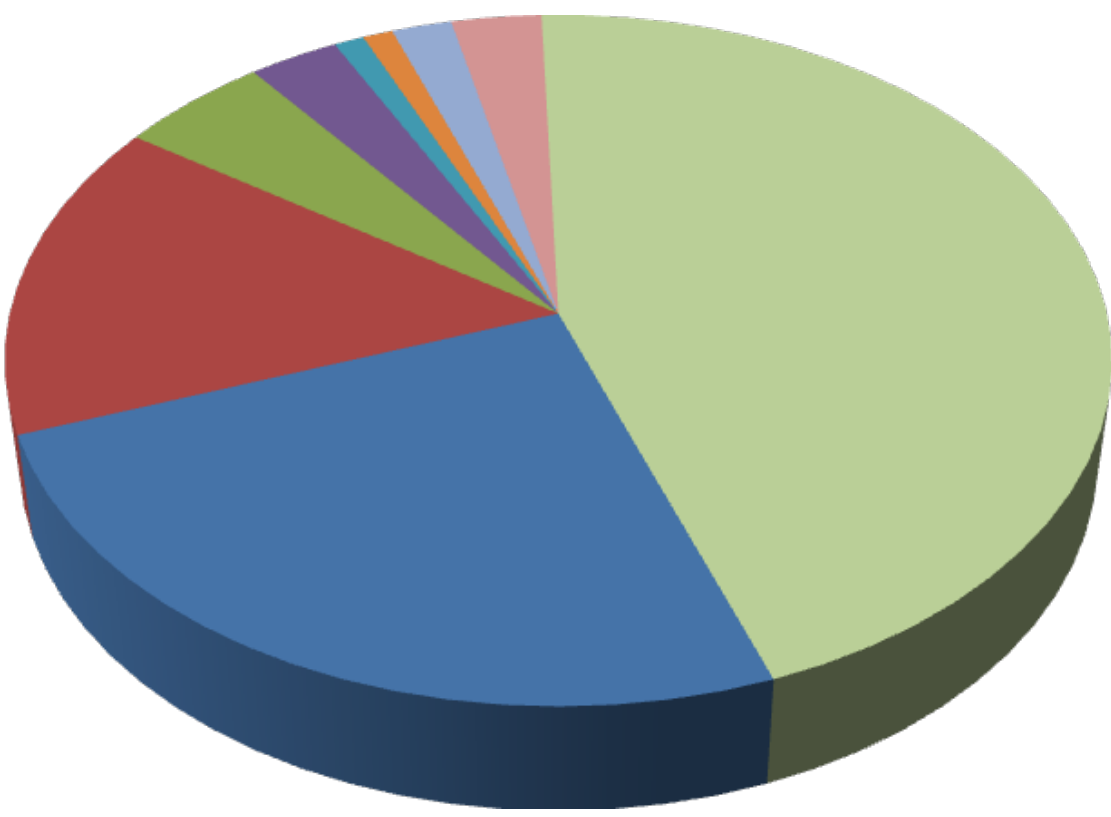

$\operatorname{KRAS}(25 \%)$

$\operatorname{EGFR}(15 \%)$

EML/ALK (5\%)

RET (3\%)

$\operatorname{BRAF}(1 \%)$

MET (1\%)

HER2 $(2 \%)$

Other $(3 \%)$

Unknown (45\%)

Figure 1: A chart on genetic alterations in adenocarcinoma of the lung.

We know we can use some of the as a target, but I believe that we'll get to know much more about these oncogenes too in the nearest future. But how about treating other types of lung cancer? There's a large group of NSCLC called squamous cell carcinoma, it accounts for about $30 \%$ of lung cancers. These tumours are much more related to tobacco smoking, and their genotype is severely mutant. Some of these tumours can even have mutant EGFR and ALK, but their extensive mutation otherwise have been a confounder in targeted treatment so far. When it comes to small cell lung cancer, it seems that it is not a unitype malignancy, but a whole group of tumours with different oncogenes, including KRAS, EGFR, BRAF, JAK3 and many more. The main advance here per 2015 is a phase II trial from 2014 that has shown a survival benefit in these patients with the use of a drug called Sunitinib. Phase III trial is yet to come, and there are some on-going studies on other types of targeted treatment for this type of lung cancer [10].

Finally, there is a new treatment possibility with cancer vaccines and antibodies. The main idea here is that any substance that is foreign to our body would form some immune response. The first time we meet an antigen - a foreigner- our body produces these Y-shaped proteins, called immunoglobulins, or in other words Antibodies. So when we happen to meet the same antigen for the second time, the antibodies recognise it as an enemy and bind it to their receptors, making the antigen visible for T-cells in the blood. The T-cell attacks the foreigner. We can either teach our body to see certain antigens on the surface of a cancer cell or we can teach the T-cell to attack and digest cancer cells more effectively. That is how the vaccines work, and there are quite a few of them out there in the on-going clinical trials. Some of the preliminary results are disappointing, some are promising, and the answers are expected to come within the nearest future. There are also few monoclonal antibodies that have shown good efficiency in combination with other types of treatment [11].

So what are the perspectives and challenges of this targeted treatment as we have it in 2015? A paradigm shift we've been witnessing in oncology in the recent years is a turn from "One size fits all" treatment to a tailored treatment, when one can be offered an effective treatment based on a couple of extra measurements. A new paradigm shift that might come into reality in the future is not going to a tailor, but going to a tailor shop, with a treatment that suites this particular patient based on many different measurements.

Personalised treatment is a promising approach and we are living in the times of great expectations. Who knows, maybe we'll be able to use the KRAS oncogene as a target some day? Maybe we should widen our search for oncogenes and survey also other cancer related genes that someday can be used as a target? And maybe we should survey other cancers too, and not only adenocarcinomas. Although it is not an official recommendation to the date, it might change too.

Moreover, there is a discussion if we should continue to use the term non-small cell lung carcinoma in lung cancer classification. Clearly, we need a new classification that takes into consideration these genetic changes that make so much difference. Maybe, instead of treating certain histology or even organ system we can rather base our treatment on the molecular profiles and sensitivities to treatment.

But with all the excitement of new therapies come also challenges. Cancer cells seem to learn how to avoid these drugs after several months, and the drugs do not work anymore. We do not know the all mechanisms for that, but it seems that a secondary mutation in the EGFR gene is the most common reason. It is presumed to develop from a resistant cell population present already at the beginning of treatment. There are several more irreversible inhibitors under development, most of them in the early clinical stage. Hopefully we will soon learn the details and would be able to control that resistance process too.

Another challenge is that even if we survey other mutations, it might take a long time until we get a new advance in targeted therapy because many of the cell mutations are interesting scientifically, but are so far useless when it comes to treatment. To the date, we still can 
only serve a minority of lung cancer patients, and we still have to learn how to use all these different mutations that are out there (Table 1).

\begin{tabular}{|l|l|}
\hline Receptors & Targeted therapy available \\
\hline EGFR & Gefitinib, Erlotinib, Afatinib \\
\hline EML / ALK & Crizotinib, Ceritinib \\
\hline MEK & Salumetinib \\
\hline BRAF & Sorafenib \\
\hline VEGFR & Bevacizumab \\
\hline PD1 & Pembrolizumab, Nivolumab \\
\hline
\end{tabular}

Table 1: Main sites for targeted therapy available to the date in lung cancer therapy.

Finally, it seems that we have managed to slow down the tumour growth. That is great news, but is that good enough? However, killing the cancer seems to be a much better idea. And therefore we still have to find the way to use the drugs we have in that war against cancer. Maybe some sort of combination treatment would be more feasible. Research progress per 2015 is impressive, and even more is to be done. Thoracic oncology remains a great area for further research and we can be looking forward to novels and advances in this field in the nearest future.

\section{References}

1. Ferlay J, Shin HR, Bray F, Forman D, Mathers C, et al. (2010) Estimates of worldwide burden of cancer in 2008: GLOBOCAN 2008. Int J Cancer 127: 2893-2917.
2. Jemal A, Bray F, Center MM, Ferlay J, Ward E, et al. (2011) Global cancer statistics. CA Cancer J Clin 61: 69-90.

3. Carney DN (2002) Lung cancer--time to move on from chemotherapy. N Engl J Med 346: 126-128.

4. Subramanian J, Waqar SN, Morgensztern D, Govindan R (2012) Recent advances in lung cancer: summary of presentations from the 47th annual meeting of the American Society of Clinical Oncology (ASCO) 2011. J Thorac Oncol 7: 260-265.

5. Reck M, Heigener DF, Mok T, Soria JC, Rabe KF (2013) Management of non-small-cell lung cancer: recent developments. Lancet 382: 709-719.

6. Weber B, Hager H2, Sorensen BS3, McCulloch T4, Mellemgaard A5, et al. (2014) EGFR mutation frequency and effectiveness of erlotinib: a prospective observational study in Danish patients with non-small cell lung cancer. Lung Cancer 83: 224-230.

7. Hutchinson L (2015) Targeted therapies: LUX-Lung trials-not all mutations are created equal. Nat Rev Clin Oncol 12: 127.

8. Niu FY, Wu YL2 (2015) Personalized treatment strategies for non-smallcell lung cancer in Chinese patients: the role of crizotinib. Onco Targets Ther 8: 999-1007.

9. Stinchcombe TE (2014) Novel agents in development for advanced nonsmall cell lung cancer. Ther Adv Med Oncol 6: 240-253.

10. Tanday S (2015) Sunitinib benefits patients with small-cell lung cancer. Lancet Oncol 16: e164.

11. Rangachari D, Brahmer JR (2013) Targeting the immune system in the treatment of non-small-cell lung cancer. Curr Treat Options Oncol 14: 580-594. 